\title{
Diagnosing turbine engine bearing structures with the aid of FAM-C and FDM-A methods
}

\author{
Andrzej Gębura, Ph. D. \\ Air Force Institute of Technology
}

\begin{abstract}
The diagnostic method FDM-A [2], based on the measurement of the pulsation component frequency modulation, and the FAM-C method, making use of the alternating current frequency, were developed in the Air Force Institute of Technology. The essence of their accuracy consists in "natural" synchronisation of the sampling signal with the angular velocity of the observed kinematic links. These methods make it possible to determine the level of wear of a subsystem and its location during normal operation of the power unit. They provide opportunities for determining numerous parameters of bearings, bearing structures, and the rotor unit. Moreover, the FDM-A method makes it possible to detect resonances in particular elements and their parameters - among others, they provide opportunities for assessing the level of the mechanic quality factor of the examined structure, i.e. the time margin of structure operation until the structure reaches the state of resonance. On the other hand, the FAM-C method provides opportunities for defining numerous parameters of the phenomena connected with the rotor unit. The diagnostic system is connected to an arbitrary point of the electric network (electric junction, for instance) supplied with the direct voltage ${ }^{1}$ or the alternating voltage ${ }^{2}$ taken from the generators driven by the examined rotating system.

The presented experimental material was recorded in operating investigations of the aircraft turbine engine unit, in which the role of "generators - observers" was played by: an aircraft DC generator and a threephase AC rate generator. Generators of this type are also used in rocket cutters with turbine engines, this way the conclusions presented in the article can be easily transferred to those objects.

During the measurements, performed on the decks of the examined airplanes and on engine test beds, the ranges and locations of assembly and wear defects were determined. Successive stages of wear of the rolling bearings were also observed.
\end{abstract}

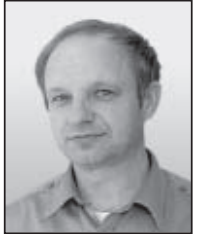

Key words: technical diagnostics, diagnosing propulsion transmission ducts, skew ${ }^{3}$, frequency modulation, characteristic set, turbine engine, rolling bearing

\section{INTRODUCTION}

Industrial development observed on the turn of the ninetieth century was a source of demand for rolling bearings, to be used in machines built in large numbers in those days. At the same time, the development of technology made it possible produce, in a mass scale, precisely machined bearing components. The bearing structures had relatively low rotational speeds, which rarely reached the level of $3000 \mathrm{rev} / \mathrm{min}$.

New challenges for rolling bearings were brought by the development of aviation - increased vibrations and the action of higher and rapidly changing temperatures made it necessary to secure higher reliability of the bearings via increasing radial clearances and more careful selection of construction materials. Even bigger challenge was connected with new constructions of jet turbine engines built after the second world war. Rotor units in these engines reached rotational speeds ranging from $10000 \mathrm{rev} /$ min to $60000 \mathrm{rev} / \mathrm{min}$, much higher than ever before.
For a relatively long time, diagnosing the technical state of rotor unit bearing supports in aircraft engines has been done using vibroacoustic methods. The vibroacoustic signal, which carries the diagnostic information, is taken from the bearing structure elements and therefore is heavily noised and damped, which makes the diagnosis extremely difficult and time consuming. This is because of the presence of strong disturbances [5] generated by vibrating metal elements of the aircraft engine construction (which is, as a rule, relatively elastic). The second factor is the attenuation of the diagnostic signal on joints between the mechanical elements and in all spaces filled with air, fuel, oils and lubricants (all these are the media revealing poor propagation of acoustic waves). And the third, last factor is the concentration of numerous vibrating elements located close to each other, which makes detecting the location of the defected objects extremely difficult.

In the article, another diagnostic method is proposed in which the diagnostic signal from the bearing supports is

This method is called FDM-A (FM- frequency modulation, D - direct current, A - method advancement level)

This method is called FAM-C (FM- frequency modulation, D - alternating current C - method advancement level- means that applications are in use in the form of automatic tester).

Also referred to as sweep. 
transmitted via mechanical joints to an aircraft generator, in which it is converted to a synchronous, digital signal. This signal can be easily processes using present-day computers. Two variants of the proposed method were named FAM-C [2] and FDM-A by the authors. In those methods the analysed diagnostic signal is coded in the frequency and phase modulation, which is (as is well known from the theory of radio wave transmission) more resistant to disturbances than the amplitude modulation. The acoustic signal is subject to two-stage sampling:

is "synchronous sampling", which consists in the conversion into a digital signal (instantaneous frequency time-history) by the "regular" deck generator

is "classical" sampling in time intervals between the above described "synchronous" sampling, done by a clock with properly selected frequency in the counter card.

In Ref. [7-10, 13] the author has presented his achievements concerning the application of the FAM-C method making use of a single phase output voltage in the deck generator for diagnosing simple cases of wear and assembly defects of power transmission boxes. These achievements included:

$\diamond$ monitoring of slips in one-way clutches,

$\diamond$ estimating skew angles of power transmission shafts and their parallel displacements,

$\diamond$ detecting cavitation phenomena in the deck generator hydraulic rotational speed stabiliser system.

Ref. [11] describes the use of a similar diagnostic method for estimating skew angles of power transmission shafts and their parallel displacements in the power transmission system in the ship engine room. The use of the three-phase measurement [13] made it possible to trace, without instrumentation change, mechanical processes revealing higher frequencies, for instance monitoring the operation of ship compressionignition engines.

Further resolution refinement was done using the signal of the DC generator output voltage. This method, named FDM-A, makes it possible to trace mechanical processes [12] revealing even higher mechanical frequencies:

$\checkmark$ monitoring the wear of toothed wheels, and estimating dimensions of tooth-to-tooth clearances

$\neg$ estimating the operation of rolling bearings.

In author's opinion, the here presented methods: FAM-C and FDM-A can become a valuable version of the non-interfering monitoring of the technical state of turbine engines. Some applications discussed in further sections indicate important advantages of these methods, such as:

- no need for connecting any sensors to the object - this role is played here by the "regular" generator mounted on the object

$\Rightarrow$ the measurement can be done at an arbitrary network point, even extremely distant from the examined object

$\rightarrow$ the primary diagnostic signal is directly "transmitted" from the examined bearing situated deep inside the structure to the generator serving as a sensor-processor via elements of the transmission construction. This way large disturbances, which can come from casing resonances, volumetric damping and other disturbances of high importance for vibroacoustic methods, can be omitted [5]

$\rightarrow$ transient loss of the "connection" between the diagnosed element and the generator-receiver is not a problem - the clearances are presented as a separate estimate (among other actions, a separate characteristic set is created), which can also be an object of parametric analysis easy automation of the diagnostic process

high speed of diagnostic data recording.

\section{METHOD DESCRIPTION}

A comprehensive description of the diagnostic methods is given in Ref. [2, $6 \div 13$ ]. It is advisable, however, to present its main elements, which are indispensable for understanding the context of the problems discussed in the article. Each assembly or wear defect, for instance skew of the splined connections in a power transmission box, is accompanied by the modulation of the output angular velocity. The modulation interval is a characteristic parameter for the type of defect and nominal angular velocity of the given kinematic pair. At the same time the level of frequency deviation (amplitude of modulations) is proportional to the scale of the defect. These modulations are transmitted, via the transmission system, to the rotor of the generator. Being a synchronous machine, the aircraft generator reflects changes of instantaneous angular velocity in the form of output voltage frequency modulation. By measuring time increments between successive zero level crosses and drawing their doubled inverses on the $\left(t, f_{i}\right)$ rectangular coordinate plane we obtain a set reflecting, in a discrete form, the course of generator rotor velocity changes. Two parameters can be attributed to each deviation, which are:

$>$ deviation time $\mathrm{t}_{\text {odi }}$

$>$ deviation amplitude $\Delta \mathrm{F}$.

The deviation time can be substituted by the process frequency $f_{p}$, according to the formula:

$$
\mathrm{f}_{\mathrm{pi}}=1 /\left(2 \mathrm{t}_{\text {odi }}\right)
$$

Each deviation can be presented on the rectangular coordinate plane as a point $\left(f_{p}, \Delta F\right)$. It was found in numerous research activities that these points tend to concentrate into sets. These sets bear the name of characteristic sets, as they characterise the wear of particular subsystems. It was found that they have different shapes, heights and locations with respect to the $\mathrm{X}$-axis.

It was also found that the change in the scale of the defect results in the change of the height $\left\{/ \Delta \mathrm{F}_{\max } /+/ \Delta \mathrm{F}_{\min } /\right\}$ of the corresponding set, while the band $0-f_{p}$ occupied by the set with respect to the $\mathrm{X}$-axis is characteristic for the type of the subsystem.

During numerous applications of the method the author has found that the presentations created in the above way as characteristic sets are favourable for a well known object, with well recognised relations between the change in the scale of the mechanical defect and the change of the characteristic set height. The use of these presentations has numerous advantages:

$\Rightarrow$ demodulation processes take a natural course directly in the deck generator, which simultaneously is a natural band-pass filter in the process of observation of mechanical phenomena

$\Rightarrow$ the electric signal recorded from the deck generator is synchronised in a natural way with the observed mechanical phenomena, as the rotor of the generator-observer is fixed to the diagnosed mechanical kinematic pairs

$\Rightarrow$ easy automation of the diagnostic process:

- each type of defect of each subsystem has reserved an individual, earlier defined characteristic band on the $\mathrm{X}$-axis

- for each band, a number of diagnostic levels (usually four: A, B, C, D) are defined on the Y-axis - depending on the height of the given set the subsystem is classified as belonging to one of these diagnostic classes 
$\Rightarrow$ easy observation of the time-histories of arbitrarily long duration in the same plane - of special importance when the signals appear stochastically

$\Rightarrow$ easy extraction of the pulsation component from a heavily modulated signal. Indeed, these extraction can also be done using partial Fourier analysis, but that analysis, unlike the FAM-C and FDM-A methods, has two disadvantages:

- spectral lines for real power transmission systems are usually broadened, which makes the diagnostic pattern obscure and difficult for automation

- that analysis neglects stochastic processes.

Despite all above named advantages of the wear presentation on the $\left(f_{p}, \Delta F\right)$ plane, for unknown objects ${ }^{4}$ it is advisable to use relations ${ }^{5} f_{i}=f(t)$ for diagnostic purposes. Based on these relations, an experienced diagnostician can perform the process of state identification of the diagnosed object in a more efficient, although also more time consuming way. In that way stochastic processes can be traced, including, for instance, a temporary stop of the rolling element in its motion around the raceway due to the local appearance of the abrasion product.

Once the characteristic sets are created based on the recorded time-histories, Fig. 3, the following parameters can be calculated:

$\star$ height of the first harmonic characteristic set - proportional to the dimension of the total radial clearance and the rotor unit unbalance

$\star$ width of the characteristic set - proportional to the rotor unit unbalance

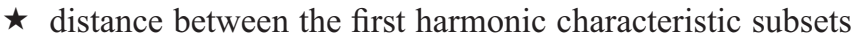
- proportional to the shape error (ovalisation, roundness deviation) of the bearing seat

$\star$ height of the main shaft first harmonic characteristic set - proportional to the rotating unit symmetry axis skew angle (between the generator shaft and the turbine shaft)

$\star$ skews and axial clearances of other rotating engine elements, such as pumps, power transmission shafts, etc.

\section{DESCRIPTION OF THE DIAGNOSED OBJECT AND THE MEASURING SYSTEM}

Turbine engines have found their immovable place in aviation. An element which is most exposed to the action of dynamic forces in those engines is the bearing cage. According to the design tradition, its only role is to separate the rolling elements, as a result of which the bearing cage is not expected to carry heavy loads. The situation of general underloading of the bearing and rapid changes increasing its load, when the bearing cage is subject to the action of impact forces, is untypical for machine design traditions. Different kinematics of the rolling elements, being the result of different friction conditions, is the origin of impact forces in the rolling unit. The energy passed to the cage during its collision with the rolling element changes its momentum in both the circumferential and radial direction, and is partially lost for an additional slip of the rolling elements on their raceways. As a result of these phenomena, the cage starts to oscillate in an undamped way between the rolling elements [6]. It also rotates, in general, around another axis than the bearing axis. The stability of the cage motion highly depends on friction conditions observed in the rolling contacts and in the areas where the cage contacts the rolling elements. According to author's experience, these forces are so large that they can provoke cracks of the separating elements in the cage, or even cracking of the bearing perimeter. Such phenomena are frequently preceded by resonance effects.

Phenomena of this type, untypical for earlier applications of the rolling bearings, were the reason why producers and institutions involved in aviation industry often carry out, on a wide scale, research activities oriented on detecting and monitoring complicated processes of rolling bearing failures in aircraft engines. Nowadays, this problem is still unsolved and is an object of concern of designers, operators, and analysers of aviation accidents.

In order to gain more detailed information on the relations between frequency modulation phenomena and bearing defects, the process of long-lasting wear of engine bearings was examined on the engine test bed, and was complemented by observations of engines directly on the decks of the airplanes. The object of investigations was a single-shaft turbine engine, Fig. 1. The main shaft is divided into the compressor shaft and the turbine shaft, which are linked together via the splined connection, Fig. 2. The shaft is supported on three rolling bearings.

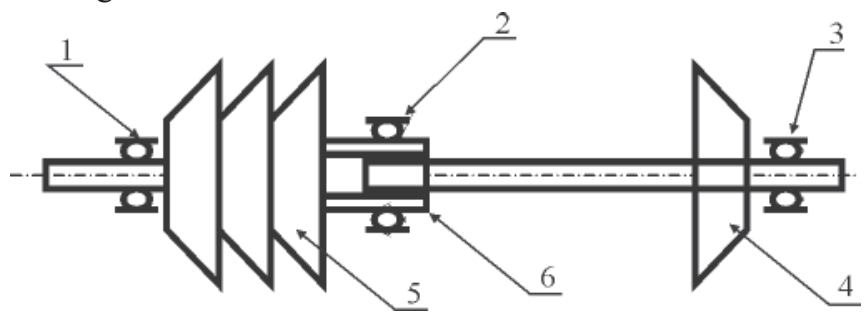

Fig. 1. Kinematic diagram of a one-watt turbine engine

1 - front bearing; 2 - central bearing, connection between two shaft parts (turbine shaft, compressor shaft); 3 -rear bearing; 4-turbine; 5 - compressor; 6 - central bearing journal

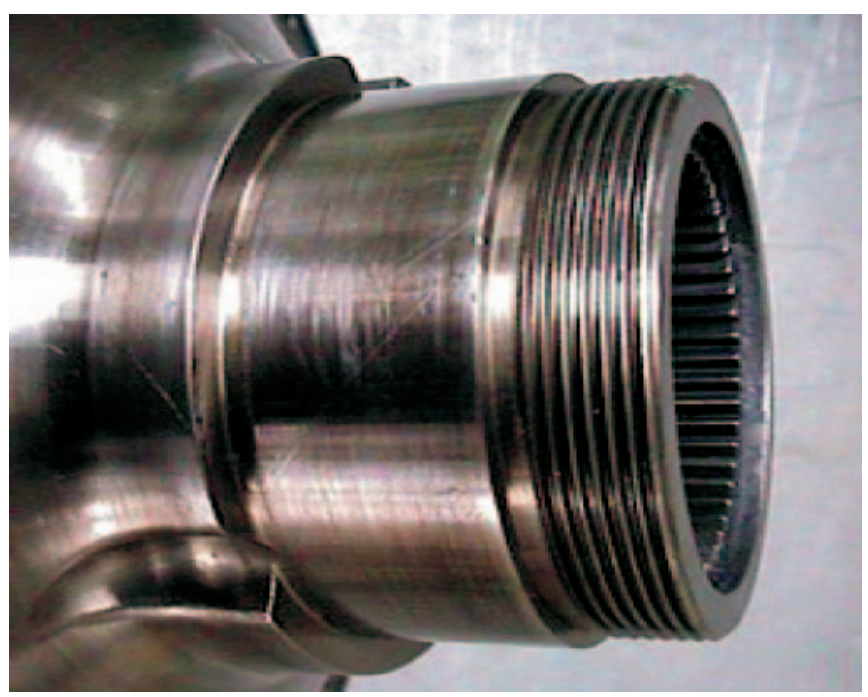

Fig. 2. Central bearing journal, connection between two shaft parts (turbine shaft, compressor shaft)

The front bearing has a different number of rolling elements that the central bearing - that is why their characteristic sets are easily recognisable using the FDM-A method, Figs. 1 and 2 . The central bearing structure is the most heavily loaded subsystem of all three engine supports, due to most difficult cooling conditions and the highest deflection of the rotor unit. The outer ring of the central bearing is pressed into an elastic sleeve, the splines of which are fixed to the engine body.

With unknown relations between the defect of the unit and changes in the depth of the generator output voltage frequency modulation. In fact, the presentation $\mathrm{fi}=f(\mathrm{t})$ has a discrete form as a set of points. In diagnostic practice, however, presentations are in use in which points are distributed with such a fine resolution that they give an impression of a continuous curve. 
Occasionally, traces of rotation (slips) of the bearing ring in the sleeve can be observed during engine repairs. Also cases are recorded of cracks of the sleeve that fixes the central bearing outer raceway to the engine body.

The inner bearing ring is pressed onto the compressor journal. The turbine shaft is introduced inside the journal by a splined connection. This connection makes it possible to transmit the torque from the turbine shaft to the compressor shaft. Longitudinal connection between these two parts is executed, in turn, by two half-rings and a special nut screwed onto the end of the central bearing journal. Breaking this connection may result in a disaster, as it disconnects the power turbine - there is no drive for pumps and other units necessary for proper engine operation. In this structure skews are frequently recorded which are the sources of additional dynamic loads, along with the forces generated by bearing assembly errors and radial clearances.

From the point of view of journal load, very dangerous are large skew angles accompanied by small radial clearances in the central support - a source of heavy bending loads of the journal. The most dangerous cases of bearing operation include slips of the inner bearing ring on the journal, as they are the sources of not only of excessive dynamic forces, but also the increased level of temperature field, which can provoke journal plasticisation and reduce its mechanical strength.

Due to the specific construction of the engine, of high importance it securing the coaxiality of the bearing seats during their assembly. Theoretically, all three bearings are to be situated along one axis, with a small permissible tolerance. Coaxiality changes lead to disturbances in bearing operation. Of high importance for each bearing is the state of the cage separating the rolling elements in the bearing. Its smooth motion guaranties correct motion of the rolling elements. The investigations were performed in two paths, Fig. 3, using signals from a DC generator (DC channel) and a three-phase AC rate generator (AC channel). These two paths complemented each other.

The three-phase AC rate generator was a source of information on situations connected with slow-speed processes, including:

* technical state of the power transmission box

* unbalance of the main shaft (with compressor and turbine), and ranges of radial clearances in bearing supports

* skew of the main shaft - assessment could be made whether the skew of the compressor shaft with respect to the turbine shaft is increasing. As a final result, an assessment can be made whether this skew does not exceed a permissible limit defined by the bearing producer

* crack of the sleeve that fixes the central bearing

* increased ovalisation (circular shape error) of the bearing seat

* number of cracked separation sections in the cage

* error of journal perpendicularity with respect to the compressor disc rotation plane

* increased torque on the engine main shaft.

The DC generator provided the information about defects connected with high-speed processes. The processes which could be observed and diagnosed include:

cooperation of the main shaft with the transverse vibration damper (central support)

increased friction force in the front bearing as a result of longitudinal movements of the compressor shaft $\left(\mathrm{h} \geq \mathrm{N}, \mathrm{p}_{\mathrm{s}} \geq 0.4\right)$

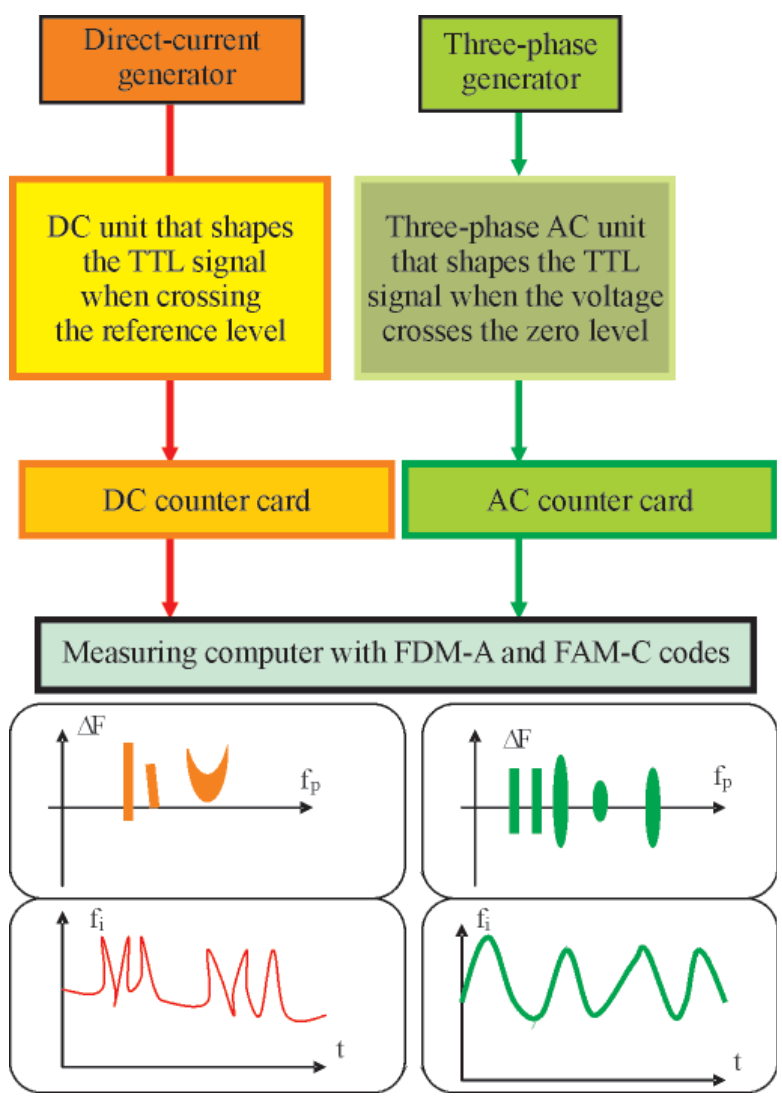

Fig. 3. Recording diagnostic signal from the examined engine using FDM-A and FAM-C methods

locking of the front bearing cage (separator) - the appearance of the $\mathrm{N}_{\mathrm{p}}$-th harmonic of the main shaft rotational speed $\left(h=N_{p}\right)$, where $N_{p}$ - number of rolling elements in the bearing

- locking of the central bearing cage (separator) - the appearance of the $\mathrm{N}_{\mathrm{s}}$-th harmonic of the main shaft rotational speed $\left(\mathrm{h}=\mathrm{N}_{\mathrm{s}}^{\mathrm{s}}\right)$

general level of wear of the bearing structure.

\section{PROBLEMS RELATING TO BEARING WEAR AND POSSIBILITIES OF THEIR OBSERVATION WITH THE AID OF FAM-C AND FDM-A METHODS}

A feature characterising the designs of all types of bearings is the type of contact between the rolling elements and the ring raceways under load. This contact is of Hertzian type: linear in the roller bearings and of point nature in the ball bearings. It is decisive for determining the permissible load of the bearing ${ }^{6}$ defined by its load capacity. The maximum load of the rolling elements resulting from the permissible Hertzian pressure in the rolling contact is a factor decisive for potential use of the bearing in a given case of load. According to Ref. [5] the highest probability that the machine defect will be detected is secured by the observation of the bearing structure, and this probability is equal to $70 \%$. In laboratory conditions, the main cause of bearing defects was the fatigue wear of the working surfaces of their elements. According to literature data, the observations of defects of rolling bearings in real operating conditions indicate that the fatigue raceway defects do not exceed $36 \%$, in general, of all causes of their withdrawal from operation, while in the

6 According to ISO-76-1978 standard [6], permissible loads are the loads at which permanent deformation in the contact of the most heavily loaded rolling element with the raceway does not exceed 0,0001 of the rolling element diameter. In the USA, the standard ANSI/AFBMA std 9,11-1978 defines the maximum permissible limit of surface pressure as equal to $4000 \mathrm{Mpa}$. 
remaining cases $55 \%$ of bearings lose their workability due to excessive friction wear, and further $9 \%$ - due to the corrosion and other destructive processes.

\section{Durability vs. load}

Fatigue durability of bearings depends on their load. As a consequence, observations of all instantaneous bearing overloads are crucial for the assessment of their lifetime. The FDM-A method makes it possible to trace, in an easy way, (high-speed) time-histories of the instantaneous velocity (DC channel), by observing the frequency, amplitude, and dynamics of retardations of the rolling elements. Indirectly, after gaining additional information from the slow-speed data recorded in the AC channel, we can also conclude about stresses taking place during rolling down the raceway.

Hence, a conclusion can be drawn that the complete aircraft engines which, diagnosed using FDM-A and FAM-C methods, reveal lower (worsened) parameters cannot be mounted on airplanes designed for tasks connected with extremely high overloads, observed in acrobatic airplanes for instance.

\section{Friction wear}

It results from the investigations carried out by the research team headed by the author that changes of clearance dimensions can be monitored in the form of a number of parameters recorded using the FDM-A and FAM-C methods. These parameters include:

- height of the characteristic set of the AC generator main shaft rotational speed first harmonic (AC measuring path) - total radial clearances

- value of the rolling coefficient $\mathrm{p}_{\mathrm{s}}$, defined as the ratio between the average angular velocity of the main symmetry axis of the bearing rolling element (roller) and the velocity of the main shaft. It is obtained from the quotient of the total frequency modulation band of the DC pulsation component in the bearing (DC measuring path) to the product of the rotational speed and the number of rolling elements in the bearing. The obtained $\mathrm{p}_{\mathrm{s}}$ value facilitates assessing the smoothness of the cage motion and makes it possible to determine the slip coefficient between the rolling elements and the raceway

- relative value of the AC path total pulsation - determining circumferential clearances between the cage window and the rolling element.

Excessive bearing clearances are the sources of the raceway resonance vibration and provoke the instability of motion in the cage/rolling element system. The resonance vibrations have the high-frequency nature (of an order of a number of $\mathrm{kHz}$ ) and can only appear when the $\mathrm{SBK}^{7}$ spectrum has the broadband nature. The presence of slips in the rolling bearing differentiates the kinematics of particular rolling elements, which, as a result, leads to fluctuations of characteristic frequencies of the kinematic excitations. Due to the presence of clearances in the kinematic pair, each disturbance in the motion of the rolling elements is a source of additional impact forces in the cage/rolling element system. The volume of the energy introduced and lost during the collision depends on friction conditions between the contacting pairs composed of the rolling elements/cage partitions and the rolling elements/ bearing raceways. Intensive abrasive wear is accompanied, in turn, by higher bearing temperature, increased volume of wear products in the lubricating medium, and intensive ageing of this medium. Also the load distribution into particular rolling elements changes unfavourably, towards more heavily loading of the element which carries the highest force.

\section{Ageing phenomena}

Ageing phenomena are, perhaps, the least recognised issues. They require extremely long time intervals of engine observation, and precise records of their standstills and storage. It is well known that the fastest process of bearing ageing is observed on engines which are stored in unfavourable maintenance conditions, in high relative humidity (over $\eta=60 \%$ ) and at large temperature changes. Especially harmful for the bearings are electrolytic corrosion processes, due to the use of various metals, with different alloy compositions (for instance, steel with different contents of carbon) and different electrochemical potential. It results from the author's experience that the engines had smaller clearances after a few months of storage.

The literature overview suggests that possible intensification of the ageing process depends strongly on changes in the operating temperature level caused by, for instance, high ambient temperature, and/or less effective cooling of the bearing due to insufficient mass flow rate of the cooling air or oil.

A very dangerous type of ageing wear is also the abovementioned plasticisation of the bearing journal.

\section{SUCCESSIVE TYPICAL STAGES OF BEARING WEAR OBSERVED USING FAM-C AND FDM-A METHODS DURING THE OBSERVATION OF LONG-LASTING WEAR PROCESSES}

According to the practical diagnostic experience, successive stages (phases) of bearing wear [5] include noise wear, vibration wear, and thermal wear.

In the examined engine the bearing cage is covered with a galvanic silver layer. In the first stage of bearing operation, i.e. the noise phase ${ }^{8}$, first we observe the decrease of the rolling resistance and the increase of radial clearances, due to wearing-in of the bearing. Then the silver is spalled out, as a result of which more and more heavy bearing operation is observed. The height of the characteristic sets of the bearings increases systematically, Fig. 6 . The turning coefficient of the central rolling bearing 9 , defined as the ratio of the total band to the frequency of the $\mathrm{N}$-th harmonic (where $\mathrm{N}$ - number of rolling elements), also increases in this time - the bearing cage rotates with increasing resistance. A recommended action in the noise phase is to observe and possibly correct the assembly errors in the engine main shaft/bearing structure system. In the above way such defects as the lack of journal perpendicularity to the rotation plane were detected in the investigations, a defect which manifested itself by increased depth of the amplitude modulation in the instantaneous frequency time-histories recorded in the AC generator path. In author's opinion, as early as in this phase of bearing wear two different tendencies of turbine engine rotor bearing structure wear can be recorded,

SBK - total shape error.

8 According to the literature [5] the dominating effects in the noise phase are macro-unevennesses of bearing elements manifesting themselves as the broad-band acoustic noise.

9 Rolling bearing turning coefficient - the ratio of the mean angular speed of the bearing rolling element (shaft) main symmetry axis to the main shaft speed. 
with two different presentation relations observed using FAM-C and FDM-A methods:

a) type of structural-and-skew wear, in which systematic increase of the first subharmonic is observed in the AC generator path (increased skew) at relatively small increment of radial clearances in the central bearing. Most likely, at this type of wear large bending forces act on the journal, which in unfavourable situations can lead to its crack. The author did not observe such a phenomenon, and was only acquainted with the results of mechanical measurements done after the airplane crash. On the other hand, in the engines observed personally by him the bending forces did not lead to journal crack. They only provoked the increased load in the front bearing, with further multielement resonance in the engine supports and strong destruction of the central bearing, Fig. 5. Certainly, these destruction phenomena refer to two next wear phases

b) type of clearance wear, in which systematic increase of the first harmonic of the $\mathrm{AC}$ generator path is observed as a result of rapid increase of the total radial clearances in the central support. At this wear form, the failure-free operation of the bearing is observed much longer than for wear type a. In some cases, an increased level of mechanical vibrations is observed for increasing time of operation. But the verifications which were carried out in that time did not reveal the state which would threat with bearing break-down. However, a literature overview suggests [16] that excessive clearances in rolling bearings can also be a source of excessive heat and lead to the destruction of the bearing structure. Indeed, an engine with bearings revealing excessive clearances has an unstable characteristic of changes of the load angle distribution into rolling elements at arbitrary manoeuvres of the airplane and that is why this state can be extremely dangerous, as intensive and uneven abrasive wear of the rolling elements can appear, accompanied by rapid increase of friction forces. In the areas of contacts between micro-unevennesses the temperature increases rapidly, reaching very high levels (flash temperature). As a result, the surface temperature of the contacting elements also increases, and so does their volumetric temperature. The temperature increase, especially in the micro-areas of friction contact, is a source of many changes, of both physical and chemical nature, in the materials used for bearing element and the lubricant.

In the second stage, the vibration phase ${ }^{\mathbf{1 0}}$, systematic decrease of the height of the characteristic sets is observed due to the termination of the process of spalling out of the galvanic layer and washing out of the older spalling-out products, done by the lubricating oil system. As a result, the clearances between the bearing structure elements increase and the bearing motion resistance decreases. Also the rolling coefficient, defined in the literature [6] as the angle of the load distribution into particular rolling elements, decreases. At this stage, large clearances are observed in the bearing. The wear process is still in progress, but the mechanism of wear is controlled by the dynamic forces acting on the moving bearing elements in the environment of increased clearances.

During the investigations a value of the rolling coefficient was recorded which does not make sense from the mathematical point of view. This means that not all rolling elements of the bearing roll down the raceway. In the vibration wear stage, situations can happen when the walls of the sleeve that fixes

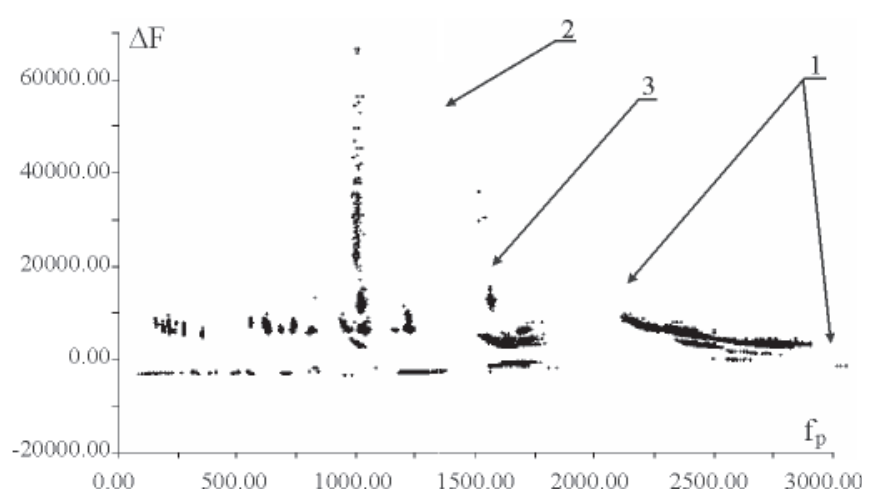

Fig. 4. Characteristic sets obtained from the DC generator path: 1 - two characteristic subsets of the central bearing and the rear bearing; 2 - characteristic set of the eighth harmonic 3 - characteristic set of the front bearing

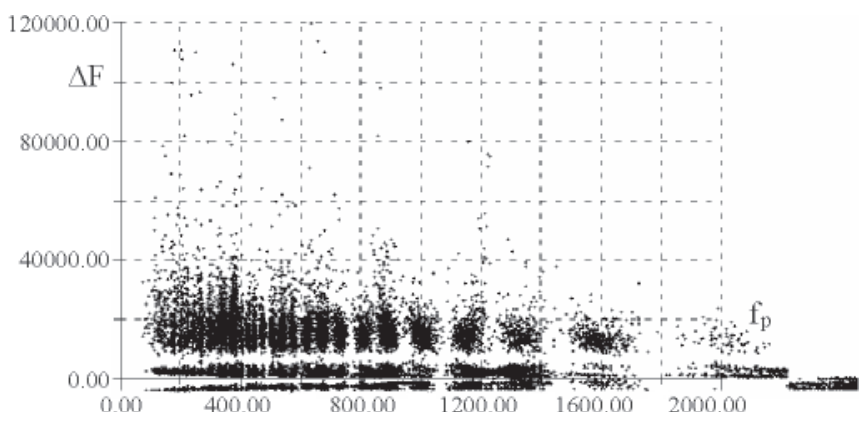

Fig. 5. Characteristic sets obtained from the DC generator path for the state of general resonance in bearing structures

the outer raceway to the engine body become thinner. This happens due to transient increase of forces locking the bearing, as a result of which the rotation-slip of the central bearing body (outer raceway) is observed in the sleeve, along with the erasing of the sleeve material due to sliding friction. The decreased thickness of the wall is observed in the FAM-C method as decreased amplitudes of the first harmonic and the first subharmonic. Most often this phenomenon is preceded by fading pulses, observed a large number of hours earlier using the FDM-A method in the DC generator path. Sometimes, due to remarkable reduction of thickness of the sleeve, or the appearance of large impact forces in the central support bearing, the sleeve cracks. Such a crack, Fig. 6, was detected using the FAM-C method in the three-phase AC rate generator path. In that time the height of the main shaft first harmonic characteristic sets decreased rapidly, by as much as nearly ten times, for all rotational speeds, except the range close to the maximum speed: $\mathrm{n}=15100 \mathrm{rev} / \mathrm{min}$ (Fig. 7).

It is well known [6] that the bearing structure becomes unstable after excessive deformations of bearing elements, shafts, and casing in operating conditions, or as a result of resonance vibrations, the reason for which is the coincidence of the exciting force frequency with the free-vibration frequency of the bearing.

A very important parameter to be traced in the vibration wear stage is the quality coefficient (Q) of the turbine engine rotor/bearing system [5]. The higher value of the quality $Q$, the smaller the damping in the system and the longer the transient processes. This way in case of large quality coefficients, each change of the nominal speed of the rotor, change of external dynamic forces acting on the rotor during manoeuvres of the airplane, and/or change of the load introduced by the units driven from the power transmission box, are the sources of

10 Of highest importance in the vibrating phase are increased radial clearances, which result in increased amplitudes of mechanical vibrations observed in the literature on vibroacoustics [5]. 


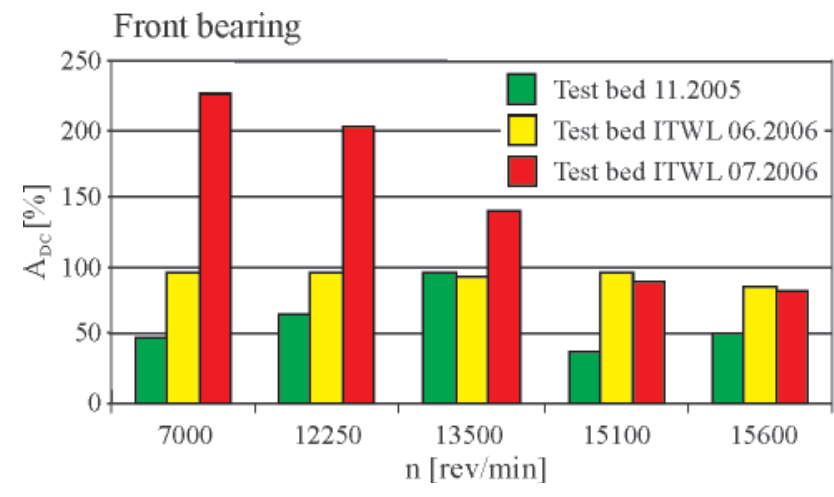

Fig. 6. Front bearing characteristic set height diagram for three successive time intervals of observation of the rolling bearing in the noise wear stage

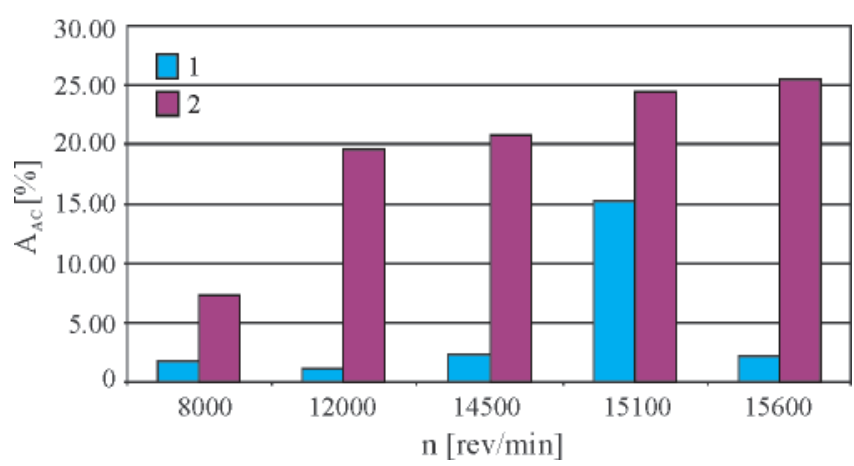

Fig. 7. AC first harmonic characteristic set height changes during the crack of the sleeve that fixes the inner bearing raceway to the engine body:

1 -after sleeve crack, 2 - before sleeve crack

strong nonlinear vibrations [15], accompanied by rubbing of the rotor elements against the casing and bearing seals, various strokes, etc. [14]. Determining the quality of the system is therefore of high importance for detecting possible causes of future failures.

According to the literature $[5,14]$, the permissible quality for rotating machines is equal to $\mathrm{Q}=5$. With the aid of the FAM-C and FDM-A methods, determining Q is relatively easy as these methods present each bearing in the form of a separate characteristic set having a well defined amplitude and band width. During the investigations, a number of cases were recorded when some symptoms of mechanical resonance were recorded - when a characteristic set, or a number of sets decrease their frequency bands, and sometimes also increase their height (so called mechanical quality of the bearing structure increases, see Fig. 4-detail 2). Sometimes these states refer to single elements of the turbine engine rotor centre, and manifest themselves as a "jump up" of a single characteristic set obtained using the FDM-A method. In other cases almost all characteristic sets increase their heights and decrease band widths. In those circumstances a multi-element resonance takes place and, according to [18], the system is in full resonance, Fig. 5. According to author's experience, those states indicate advanced level of destruction of the bearing structure, Fig. 8. Before disassembly, this bearing revealed $\mathrm{Q}>11$. During the disassembly of the bearing working in the resonance state for a relatively long time we can observe longitudinal indents on the raceways, like those reported in the literature.

When the slip of the rolling elements over the bearing raceway becomes more intensive, the motion of the majority of the rolling elements may stop completely - the phase of the thermal wear begins. In this time the volumes of the heat generated in the bearing structure are so large that they cannot be fully moved away by the oil system. As a result, the strength of the material structure of particular elements of the bearing decreases, which leads to excessive increase of windows in the separator cage, or even breaking the separation, Fig. 8. This state of bearing structure is presented in the instantaneous frequency time-histories $f_{i}=f(t)$ recorded in the AC path as repeatable, with respect to the shape and parameters, groups of pulses with the pulse numbers in a series proportional to the number of broken cells. Simultaneously, the pulsation amplitude increases from the level of about $10 \%$ up to $160 \%$. The increased temperature is also a source of thermal deformation of the central bearing ring, which easily looses clamp on the journal and is subject to slips.

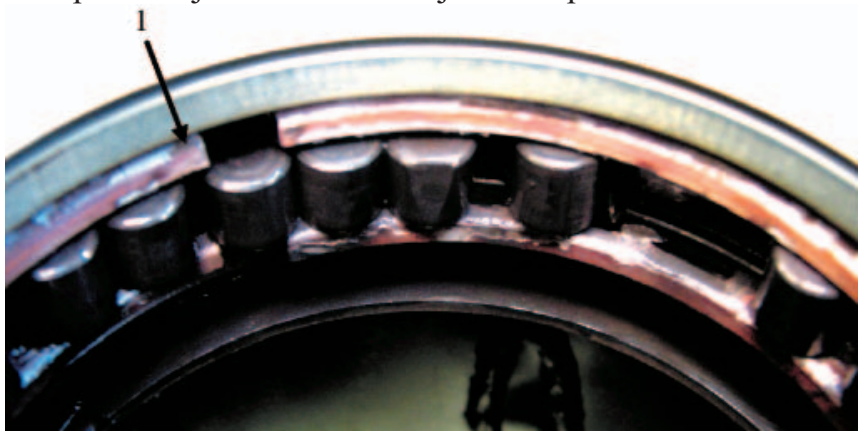

Fig. 8. Damaged central bearing, earlier diagnosed using the FAM-C method: $\mathbf{1}$ - broken cage separator ring

Using the FDM-A method in the DC generator path we can precisely determine both the angle of these slips and the frequency of their occurrence. For this purpose the times of duration and the times of repetition of the fading pulses in the instantaneous frequency time-history $\mathrm{f}_{\mathrm{i}}=\mathrm{f}(\mathrm{t})$ are observed and calculated.

In author's opinion, the most dangerous course of thermal wear stage, with respect to possible final effects, is that taking place at relatively small radial clearances ${ }^{11}$ in the central support bearing structure. In those circumstances, at large forces which tend to skew the two main shaft parts, the load is not effectively passed to the front support bearing and large part of the bending force is carried by the central bearing journal. All this can lead to the crack of the journal.

\section{ASSEMBLY ERRORS OBSERVED USING FAM-C AND FDM-A METHODS}

Bearing support assembly errors should be made distinctive and be analysed independently of the wear processes. They can act towards accelerating or delaying the time of action of particular wear stages during the bearing operation. This group of errors includes:

- radial clearances of individual bearings

- excessive circumferential clearances

- error of misalignment of three bearing supports

- error of turbine or compressor unbalance

- error of bearing seat ovalisation

error of skew of the two shaft parts

- error of compressor journal perpendicularity.

Excessive radial clearances manifest themselves in the DC generator path as the increased amplitude of the characteristic set (presentation $\Delta F=f\left(f_{p}\right)$ ) of the central bearing. The excessive

11 Small value of the radial clearance can be easily determined using the FAM-C method by detecting a relatively small amplitude of the first harmonic characteristic set on the presentation obtained from the AC generator path, and from small value (below 0.4 ) of the turning coefficient of this bearing, calculated using the FDM-A method. 
circumferential clearance, in turn, manifests itself in the AC current generator path in the form of specific undercuts observed in the time-history $f_{i}=f(t)$. In general, all characteristics of the rolling coefficient are inversely proportional to the rotational speed, which can be easily explained as the effect of the increasing hydrodynamic forces which decrease the rolling friction resistance. Long-lasting observations, complemented by mechanical measurements, have led to a conclusion that if an inflexion point in the form of a minimum appears on the rolling characteristic, Fig. 9, this means remarkable misalignment between the bearing supports.

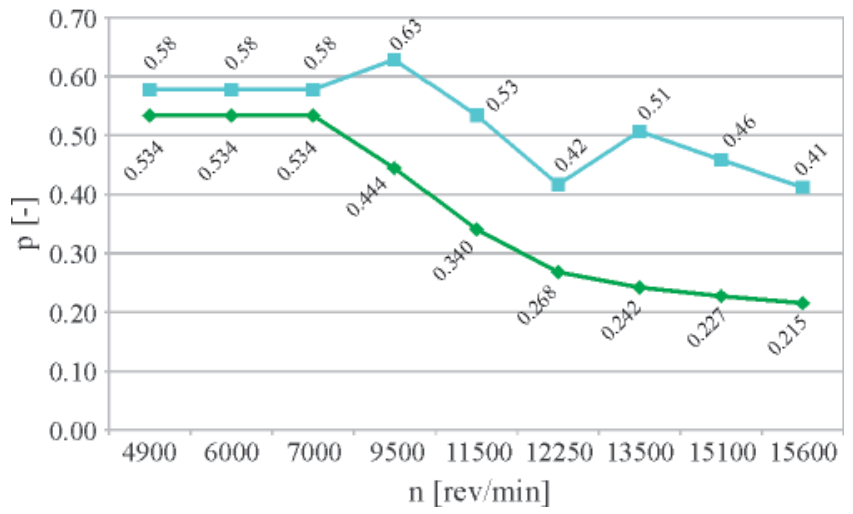

Fig. 9. Changes of central support bearing rolling coefficient: upper curve - for negative misalignment, lower curve - without misalignment error

The turbine or compressor unbalance error manifests itself in the presentations of the AC current generator paths as the increased amplitude of the characteristic set (presentation $\Delta F=f\left(f_{p}\right)$ of the main shaft rotational speed first harmonic), accompanied by the widening of this band. If the bearing structure ovalisation error takes place, this set breaks down into two vertical characteristic sets. Skewing of the connections linking the two shaft parts manifests itself as increased height of the first subharmonic characteristic sets. The compressor journal perpendicularity error can be assessed by measuring the amplitude modulation depth in presentations $\mathrm{f}_{\mathrm{i}}=\mathrm{f}(\mathrm{t})$.

\section{CONCLUSIONS}

The article presents the applications of the diagnostic methods FAM-C and FDM-A, which base on the analysis of output voltage frequency modulation parameters, for diagnosing technical states of turbine engine bearing supports. The use of these methods makes it possible to detect relatively early a defect in the diagnosed subsystem, before it becomes dangerous for the safety of airplane motion, for instance. Various assembly errors can be detected this way, and wear effects taking place in bearing structures can be monitored. Numerous parameters of the bearing operation can be traced, including: changes of friction resistance, changes of radial clearances in the bearing, changes of circumferential clearances between the cage and the rolling element, changes of the rolling coefficient. Moreover, it is possible to observe the phenomena taking place in the rotor unit, including: the skew between the turbine shaft and the generator shaft, and/or perpendicularity errors between the journal symmetry axis and the compressor disc rotation plane. Many hours earlier than when using the "traditional" methods we can observe, without interfering into the system, numerous wear phenomena that lead to dangerous failures of turbine engine bearing structures, such as bearing journal plasticisation, and/or disintegration of the separation gaps in the cage or of the entire circuit. Systematic use of the FAM-C and FDM-A methods makes it possible to determine, in a precise way, a safe time instant when the operation of the diagnosed object is to be stopped. The presented methods are of general use and can be successfully applied for diagnosing technical states of turbine engines used in watercraft.

\section{BIBLIOGRAPHY}

1. Abramov B. I.: Waddle wheel with tooth primary form, Kharkov, Ukraine, 1968

2. Biarda D., Falkowski P., Gębura A., Kowalczyk A.: Patent description PL 175664B1: Method of technical diagnosing of coupling elements in an engine, in particular, aircraft combustion engine with AC generator (in Polish), submitted on 08.07.1996, patent granted on 29.01.1999

3. Borgoń J., Stukonis M., Szymczak J.: Can damages of splined connections in aircraft engines be a source of accidents in aviation (in Polish), ITWL report no. 311/93, [in] Proc. Conf. on "Technical problems of operation and reliability of military aircraft", Kiekrz 1993

4. Bułgakow E. B., Gałobanow W., Klimow A.W.: Informacjonno - izmieritielnaja sistiema kontrolia sostojania aviacionnych i obszcziemaszinostroitielnych rieduktorov, privodov i korobok pieriedacz „Informacionnyj matieriał”, Centralny Lotniczy Instytut Konstrukcji Napędów im. P. I. Baranowa, Moscow 1990

5. Cempel Cz.: Fundamentals of vibroacoustic machine diagnostics (in Polish). WNT, Warsaw 1982

6. Furmanek S., Kraszewski Z.: Reliability of rolling bearings (in Polish). Wydawnictwa Przemysłowe WEMA, Warsaw 1989

7. Gębura A., Falkowski P., Kowalczyk A.: Airborne generators as diagnostic sensors of a power transmission system, 5-th International Conference Aircraft and Helicopters Diagnostic AIRDIAG'97, Warsaw 1997

8. Gębura A.: Relations between generator output voltage frequency modulation and selected defects of the power transmission system (in Polish).. [in:] "Aircraft turbine engines in problem approach"; edited by M. Orkisz, Polskie NaukowoTechniczne Towarzystwo Eksploatacyjne, Lublin 2000

9. Gębura A.: Skews of splined connections vs. generator frequency modulation (in Polish). Zagadnienia Eksploatacji Maszyn, vol. 4/99(120)

10.Gębura A.: Diagnostic of aircraft power transmission track based on the analysis of generator's frequency, Journal of Technical Physics, No. 1/2002

11.Gębura A., Radoń T., Tokarski T.: Diagnosing power transmission systems based on the observation of generator output voltage frequency changes (in Polish). II International Scientific and Technical Conference "Expo-Diesel \&Gas Turbine'01", Gdańsk-Międzyzdroje-Kopenhaga 2001

12.Gębura A.: Pulsations of the deck DC generator output voltage as a source of diagnostic information about the state of the power transmission (in Polish). Zagadnienia Eksploatacji Maszyn, vol. 1 (133) 2003

13.Gębura A.: Possibilities of FAM-C method in diagnosing ship power plants, Polish Maritime Research, No. 2 (36), Vol. 10, 2003

14.Bently-Nevada Application Notes Machinery Protection and Diagnostic Topics, B-N, Minden, Nevada USA

15.Harris C. M., Crede C. E.: Shock and vibration handbook, Self excided vibration, New York, McGraw-Hill 1976

16.Krzemiński, H.: Rolling bearings (in Polish). PWN, Warsaw 1985

17.Moczulski W.: Method of vibroacoustic examination of rotating machines in start-up or shutdown conditions (in Polish). $\mathrm{PhD}$. thesis, Silesian University of Technology, Gliwice 1984

18.Andrejewicz J.: Chaos and synchronisation in physical systems (in Polish), Monographs, Łódź 1995.

\section{CONTACT WITH THE AUTHOR}

Andrzej Gębura, Ph. D.

Air Force Institute of Technology, Księcia Bolesława 6, 01-494 Warsaw, POLAND P.O. box 96

e-mail: andrzej.gebura@itwl.pl 